\title{
IPTEKS PENINGKATAN LABA PADA PT. BANK RAKYAT INDONESIA (PERSERO) TBK
}

\author{
Yelfindi Purba' ${ }^{1}$ Ventje Ilat ${ }^{2}$ \\ 1,2Jurusan Akuntansi, Fakultas Ekonomi dan Bisnis Universitas Sam Ratulangi, Jl. Kampus Unsrat, Manado, \\ 95115, Indonesia \\ E-mail:oeipurba@yahoo.com
}

\begin{abstract}
Technological advances affect all aspects of life today, not least in the financial sector, namely banking. Banks are one of the institutions that affect the economy, banks also help people in managing their finances. For this reason, the writing of this article aims to see the bank's business as a customer centered trust business, in utilizing technological advancement to improve the efficiency of operational activities and service quality, and competitiveness which also includes increasing the number of customer so as to reduce operating costs which will ultimately increase profits bank.
\end{abstract}

Keywords: technology advancement, banking profit

\section{PENDAHULUAN}

Teknologi di abad ke 21 kini telah menjadi konsumsi aktif masyarakat. Banyaknya inovasi diciptakan untuk memudahkan dan memberi manfaat bagi kehidupan manusia. Otak manusia belajar dan beradapasi begitu cepat dengan perkembangan teknologi, teknologi yang menawarkan kemudahan membuat masyarakat terpacu terus untuk mengejarnya. Teknologi pada prinsipnya bertujuan untuk melayani kebutuhan informasi secara tepat waktu (fast), tepat guna (accurate), dan tepat sasaran (relevant). Satu hal yang tidak bisa untuk kita daur ulang adalah waktu. Setiap orang diburu dengan pekerjaan, tanggung jawab serta target, untuk sebagian orang waktu adalah uang. Untuk itu kecepatan dan kemudahan dalam menyelesaikan aktivitas sangat diperlukan, bahkan sebagian besar orang mau untuk membayar lebih demi hal tersebut.

Di Indonesia 20 persen dari populasi di atas 15 tahun memiliki akses terhadap layanan finansial. Artinya kemudahan akses masyarakat terhadap sistem perbankan dapat meningkatkan pertumbuhan transaksi perbankan. Bank yaitu usaha dalam bentuk lembaga keuangan yang menghimpun dan menyalurkan dana, juga menyediakan layanan jasa lainnya dengan tujuan profit untuk meningkatkan taraf hidup masyarakat. Dengan kata lain bisnis bank adalah bisnis kepercayaan. Jika bank beroperasi sampai menghasilkan kerugian maka dapat menghilangkan rasa kepercayaan hingga menyulitkan bank tersebut berkembang. Bank layaknya perusahaan selalu berupaya untuk menghasilkan pendapatan seperti yang diharapkan bahwa Profitability is The Sovereign Creterion of The Enterprise. Bank harus berusaha agar pendapatan yang dihasilkan dapat menutup biaya yang dikeluarkan.

Penggunaan teknologi informasi dan komunikasi diperbankan nasional relatif lebih maju dibandingkan sektor lainnya.Industri perbankan di dalam negeri terus bergeliat. Setiap bank terus berinovasi demi menarik nasabah lebih besar lagi. Di era kekinian saat ini, setiap perbankan berupaya keras untuk selalu mengaplikasikan berbagai kecanggihan teknologi informasi demi kemudahan, kenyamanan dan kepuasan nasabah. Cara bank memanfaatkan teknologi untuk menghadirkan inovasi yang mempermudah nasabahnya bertransaksi inilah yang akan menarik lebih banyak nasabah. Perkembangan teknologi mengikuti kemajuan ilmu pengetahuan. Kemajuan teknologi membuat manusia melakukan aktifitasnya dalam cara yang baru, mudah dan praktis. Terkait dengan kemajuan teknologi di atas, maka penulis akan 
menyajikan bagaimana dampak kemajuan teknologi terhadap peningkatan laba yang juga dipengaruhi beberapa faktor diantaranya ialah tingkat penjualan (Angkoso:2006) perbankan dengan mengukurnya dengan menentukkan angka dengan milihat presentasi atribut yang diukur (Nunnally \& Bernstein:1994) dengan melihat beberapa faktor.

\section{TINJAUAN PUSTAKA}

Teknologi. Menurut Y.Maryono \& B.Patmi Istiana, Teknologi dikembangkan dan diterapankan dalam bentuk atau wujud peralatan dan sistem, guna membantu manusia dalam menyelesaikan permasalahan permasalahan sehari-hari (Y.Maryono \& B.Patmi Istiana:2007). Dampak kemajuan dari pengembangan teknologi telah merambah ke berbagai bidang, mulai dari sektor ekonomi, pertanian, informasi komunikasi, transportasi, medis dan pendidikan.

Perbankan dan Teknologi. Menurut UU Negara Republik Indonesia Nomor 10 Tahun 1998, bank merupakan salah satu lembaga keuangan yang mengumpulkan dana dari masyarakat (simpanan/tabungan) kemudian disalurkan kembali ke masyarakat (kredit/pinjaman) serta berbagai jasa lainnya. Oleh karena itu bank menjadi unggul dari lembaga keuangan yang lainnya. Pendapatan yang diperoleh bank merupakan selisih antara bunga simpanan dan bunga kredit, dan juga antaranya adalah biaya administrasi, biaya provisi dan komisi, biaya kirim, biaya tagih, biaya sewa, bank card, travelers cheque, juga letter of credit. Setiap layanan jasa diatas yang ditawarkan oleh bank, memerlukan waktu untuk memproses kebutuhan transaksi setiap nasabahnya, oleh karena itu sebagian besar perbankan berinovasi dengan kemajuan teknologi yang sedang berkembang pesat ini agar layanan tersebut dapat dilakukan dengan lebih efektif dan efisien. Saat ini sebagian besar layanan perbankan yang sudah memanfaatkan kecanggihan teknologi tersebut, yang sudah biasa kita dengar adalah Electronic Banking. Electronic Banking termasuk dalam teknologi yang banyak digunakan oleh masyarakat. E-banking membantu pihak bank dan masyarakat dalam mempermudah proses-proses transaksi. Banyak perusahaan saat ini sudah menerapkan sistem internal maupun pencatatan dengan menggunakan teknologi komputer. Kemudahan yang dapat dirasakan dengan adanya kemajuan teknologi dibidang perbankan seperti transfer uang yang dibisa dilakukan 24 jam melalui Mobile Banking atau juga ATM (Auto Teller Machine).

Laba. Laba merupakan tujuan dari berdirinya suatu perusahaan. Laba dihasilkan dari adanya pendapatan yang kemudian dikurangi biaya dan juga pajak. Menurut Harahap (2009) laba adalah penghasilan selama satu periode akuntansi yang dikurangi dengan biaya-biaya yang terjadi. Hasil perhitungan laba juga berkaitan dengan keperluan manajemen untuk pengambilan keputusan dan evaluasi serta juga kepentingan bagi para investor (Zaenal Fanani : 2010). Ikatan Akuntansi Indonesia (2012:12) kata laba juga digunakan untuk mengukur hasil kinerja perusahaan. Akuntansi adalah serangkaian proses untuk menghasilkan laporan keuangan, dari laporan keuangan ini bank akan mendapatkan informasi keuangan yang nantinya akan digunakan untuk pihak manajemen dalam evaluasi hasil kinerja bank dan keputusan yang akan diambil untuk periode akan datang. Dalam laporan keuangan terdapat laporan laba rugi, untuk itu laporan mengenai laba sangat penting dalam proses kegiatan perbankan.

\section{Alasan Masyarakat Lebih Memilih Digital Banking}

1. Meningkatkan mobilitas

Contohnya kebutuhan untuk pengiriman uang, yang cukup merepotkan. Datang ke bank menunggu antrian panjang, mengisi banyaknya formulir dan lain sebagainya membuat banyak orang menjadi malas untuk melakukannya. Namun dengan hadirnya internet banking, dengan fitur-fitur yang mempermudah masyarakat dalam bertransaksi keuangan maka semua orang dapat melakukan transaksinya sendiri hanya dengan menggunakan aplikasi internet banking. 
2. Memperbesar kesempatan

Beralihnya kebiasaan belanja tradisional menjadi online shoppingjuga kini menjadi alasan digital banking akan sangat membantu. Selain kesempatan yang lebih besar untuk mendapatkan apa yang diinginkan, juga memberikan kesempatan untuk menikmati hidup tanpa perlu lagi merasakan rumitnya melakukan transaksi.

3. Sebuah pilihan ramah lingkungan

Banyaknya pelanggan dari sebuah perusahaan perbankan dan berbagai dokumen yang harus disediakan tiap kali transaksi. Tentu saja akan membutuhkan kertas dalam jumlah banyak. Dengan meinggalkan cara lama dengan dengan yang lebih ramah lingkungan, digital banking memungkinkan semua data disimpan lebih aman secara digital. Yang selain memperoleh manfaatnya, juga turut berkontribusi dalam pelestarian lingkungan dengan mengurangi jumlah penggunaan kertas.

4. Mudah dan praktis

Tujuan utama adanya digital banking adalah untuk memberikan pengalaman menyenangkan bagi nasabah. Digital banking siapkan untuk digunakan oleh segala usia, tanpa mengkhawatirkan akan kerumitan penggunaannya, siap untuk memberikan pengalaman perbankan yang baik, mudah, cepat dan pastinya tidak menggangu aktivitas.

\section{METODE DAN TEKNIK PENERAPAN IPTEKS}

\subsection{Metode Penerapan Ipteks}

Metode ipteks yang diterapkan adalah konsep laba dalam tataran sintaktik menurut Eldon S. Hendriksen \& Michael F Van Breda.

\subsection{Teknik Penerapan Ipteks}

Teknik ipteks yang diterapkan adalah konsep laba dalam tataran sintaktik (menurut Eldon S. Hendriksen\& Michael F Van Breda, dalam bukunya Accounting Theory edisi kelima 1992:238) tentang cara pengukuran laba yang berdasar pada prosedur akuntansi yang juga objektif, hingga laba dapat ditampilkan dalam laporan keuangan. Terdapat tiga cara pendekatan dalam mengukur laba yaitu pertama pendekatan transaksi (cash basis), kedua pendekatan kegiatan (accrual basis), dan terakhir pendekatan pertahanan kapital.

\section{PEMBAHASAN}

\subsection{Gambaran Objek Penerapan Ipteks}

Bank Rakyat Indonesia (BRI) merupakan bank pemerintah. Saat pertama didirikan BRI dengan nama De Poerwokertosche Hulp en Spaarbank der Inlandsche Hoofden yang artinya Bank Bantuan dan Simpanan Milik Kaum Priyayi Purwokerto di Purwokerto, Jawa Tengah oleh Raden Bei Aria Wirjaatmadja tanggal 16 Desemeber 1895 sebelum Indonesia merdeka. Yang menjadikan BRI juga sebagai bank pertama milik Negara. Hingga saat ini BRI tetap konsisten dalam memberikan pelayanannya kepada masyarakat Indonesia terutama masyarakat menengah kebawah. ( Website resmi PT.Bank Rakyat Indonesia (Persero) Tbk, http://bri.co.id>tentang-bri ).

\subsection{Pembahasan}

Pengukuran laba dibagi menjadi 3 yaitu :

1. Pendekatan Transaksi (Cash Basic).

Hanya pada saat terjadi transaksi tunai maka kegaiatan tersebut akan masuk dan diukur serta diakui sebagai laba. Hal juga terkait dengan pengakuan pendapatan dan biaya. Dengan adanya peningkatan kapasitas dalam teknologi, yang semakin memudahkan perusahaan dan terutama nasabah dalam bertransaksi, maka akan semakin banyak orang yang akan mempercayai PT. Bank Rakyat Indonesia dalam 
membantu mereke mengelola keuangannya. Hal ini secara langsung akan meningkatkan transaksi yang korelasinya pada peningkatan laba perusahaan.

2) Pendekatan Kegiatan (Accrual Basic)

Laba tetap diakui dan dicatat saat terjadinya kegiatan operasi perusahaan (baik produksi, pengkreditan, pembayaran, dan transaksi lainnya). Tempo dulu saat melakukan suatu transaksi akan memakan penggunaan kertas yang cukup banyak. Namun saat telah terjadi kemajuan teknologi dibidang perbankan, maka bank tidak perlu lagi mengeluarkan biaya lebih untuk produksi kertas karena saat ini PT. Bank Rakyat Indonesia telah menggunakan sistem BRInet untuk memudahkan perusahaan (internal) dalam mengelola laporan keuangannya.

3) Pendekatan Pertahanan Kapital

Dalam pendekatan ini laba diukur atas dasar aset dan kewajiban. Perbandingan aset dan kewajiban dengan mengukur kapital atas dua periode yang berbeda. Hal ini dapat dibuktikan bahwa PT. Bank Rakyat Indonesia (Persero) Tbk, membukukan laba bersih Rp.18,687 triliun pada tahun 2012. Perolehan tersebut tercatat naik sebesar $23,86 \%$ dari tahun sebelumnya.

\begin{tabular}{lrr}
\hline \multicolumn{1}{c}{$\begin{array}{c}\text { Data Keuangan BRI } \\
\text { dalam Rp. Miliar }\end{array}$} & \multicolumn{2}{c}{ Angka dari Laporan Keuangan } \\
\hline Laba Rugi & $\mathbf{2 0 1 1}$ & $\mathbf{2 0 1 2}$ \\
Pendapatan Bunga Pinjaman & 115 & \\
Pendapatan Bunga Simpanan & 87 & 92 \\
Pendapatan Operasional Perushaan & 7 & 9 \\
Biaya Operasional Perusahaan & $(27)$ & $(29)$ \\
Biaya Lain-lain & $(6)$ & $(3)$ \\
Laba (Sebelum Pajak) & 29 & 34 \\
Laba Bersih Tahun Berjalan & 25 & 29 \\
Laba rugi komprehensif & 25 & 29 \\
Laba Bersih per Saham (Rp) & $\mathbf{2 5 5}$ & $\mathbf{2 7 9}$ \\
\hline Lapora Keuangan Inim PT. Bank Rakyat
\end{tabular}

Laporan Keuangan Interim PT. Bank Rakyat Indonesia (Persero) Tbk, 2012. Manajemen PT.BRI sesuai Standar Akuntansi Keuangan di Indonesia)

Informasi Keuangan interim diatas diambil dari laporan keuangan interim PT. Bank Rakyat Indonesia (Persero) Tbk, 2012. Yang disusun oleh manajemen Bank sesuai dengan Standar Akuntansi Keuangan di Indonesia. Kenaikan laba ditahun 2012 ini juga dipengaruhi oleh salah satu faktor kemajuan teknolgi, yaitu PT.Bank Rakyat Indonesia (Persero) Tbk, pada tahun 2012 mengeluarkan layanan terbaru yaitu BRI Mobile, internet banking BRI, call BRI serta info BRI seperti ATM Locater. Sistem layanan terbaru ini memungkinkan setiap nasabah BRI untuk melakukan transaksi sendiri melalui smartphone. Saat melaunching sistem ini BRI telah menargetkan untuk penggunaan BRI mobile mencapai 4,5 juta user dan 7 juta transaksi sampai akhir tahun. 


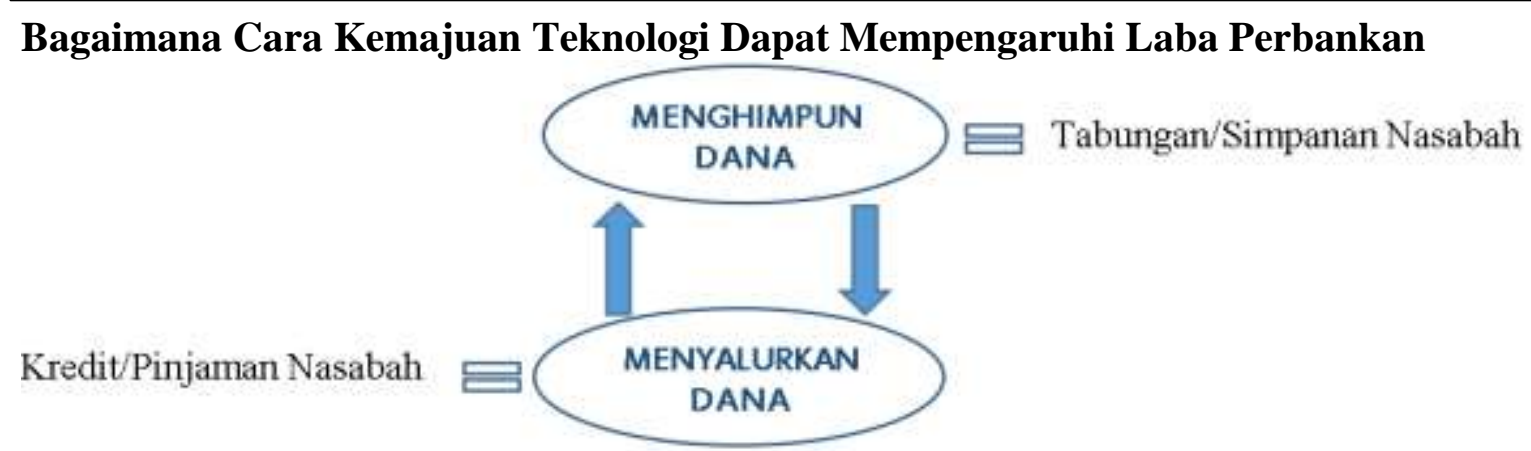

Gambar 1. skema arus perputaran keuangan bank

Tugas utama bank adalah seperti gambar 1. dari kegiatan utama tersebutlah bank akan menghasilkan laba. Saat bank di dirikan, bank tersebut pasti memiliki investor atau pemegang sahamnya baik itu perorangan (swasta) ataupun pemerintah. Namun untuk membuat suatu bank berkembang maka diperlukan tabungan / simpanan dari nasabah nasabah yang kelebihan dana yang nantinya akan menambah jumlah untuk disalurkan kembali sebagai kredit / pinjaman kepada nasabah nasabah yang kekurangan dana.

Sebenarnya poin utama untuk mengembangkan hubungan saling menguntungkan yang lebih kuat antara bank dengan nasabahnya adalah dengan membangun loyalti nasabah dan pertumbuhan yang berkesinambungan. Tetapi kemajuan teknologi yang mempercepat dan mempermudah setiap kebutuhan inilah yang akan menarik lebih banyak nasabah untuk bermitra pada suatu bank yang dapat memberikan pelayanan pelayanan yang dibutuhkan.Semua softaware dapat diakses berkat tersedianya portal khusus yang dimiliki oleh setiap bank. Walaupun suatu bank memang membutuhkan biaya lebih untuk mengupgrade kapasitas mereka agar bisa memproduksi teknologi teknologi tersebut.

Menurut Atkinson et al (2007:89) Biaya merupakan nilai dari suatu barang/jasa guna menghasilkan manfaat dimasa kini maupun masa akan datang, dan juga menciptakan suatu produk yang bisa diperdagangkan guna memperoleh laba. Jadi saat bank mengeluarkan uang untuk meningkatkan kapasitas pelayanannya dalam mengikuti kemajuan teknologi, hal itu bukanlah menjadi suatu beban melainkan biaya. Saat teknologi suatu perbankan selangkah lebih maju dibanding yang lain, maka masyarakat akan cenderung memilihnya karena mengingat manusia sangat terpacu untuk mengejar sesuatu yang baru, mudah dan praktis. Saat jumlah nasabah suatu bank meningkat, maka tabungan / simpanan nasabah yang ada dibank juga meningkat dan dana yang ada di bank untuk disalurkan kepada nasabah yang kekurangan dana (kredit / pinjaman) juga ikut bertambah. Hal ini akan membuat bank sebagai agen kepercayaan akan menerima lebih banyak bunga dari hasil tabungan maupun kredit, dan juga hasil dari biaya transaksi transaksi yang dilakukan oleh nasabah.Saat pendapatan suatu bank bertambah maka secara otomatis laba bank akan ikut mengalami peningkatan.

\section{KESIMPULAN DAN SARAN}

\subsection{Kesimpulan}

PT.Bank Rakyat Indonesia (Persero) Tbk, sangat cermat dalam meningkatkan kapasitasnya baik dalam pelayanan maupun produksi. Kemajuan teknologi yang diciptakan juga sesuai dengan konsep laba dalam tataran sintaktik yakni pengukuran laba dengan pendekatan transaksi, pendekapatan kegiatan dan pendekatan pertahanan kapital. Saat teknologi perbankan ditingkatkan hal ini akan mengurangi berbagai biaya yang biasa dilakukan secara tradisional, dan menambah pendapatan yang dihasilkan dari kepercayaan nasabah, baik nasabah lama maupun nasabah baru. Toeri ini dapat dibuktikan dengan melihat 
kemajuan teknologi yang diciptakan PT.Bank Rakyat Indonesia (Persero) Tbk, dengan peningkatan laba yang dihasilkan.

\subsection{Saran}

Teknologi membantu perbankan meminimalisir biaya-biaya, menginovasi sistem pelayanan, memberikan ciri tersendiri agar bank semakin unggul, membantu bank berkembang pesat, menarik investor serta yang paling penting adalah meningkatkan laba serta mengimplementasikan strategi strageti kompetitif. Untuk itu bank harus meningkatkan kapasitasnya terlebih khusus dibidang teknologi. Dengan memperhatikan teori dalam konsep laba dalam tataran sintaktik maka pengembangan teknologi yang diciptakan akan meningkatkan laba yang diharapkan.

\section{DAFTAR PUSTAKA}

Angkoso. (2006). Pengaruh Rasio Keuangan Terhadap Pertumbuhan Laba Pada Perusahaan Industri Barang Konsumsi yang Terdaftar di BEI. Skripsi, Fakultas Ekonomi, Universitas Sumatera Utara.

Nunnally, Bernstein, I.H. 1994. Psychometric Theory, Edisi ke 3. New York : McGraw Hill

Y.Maryono \& B.Patmi Istiana, 2007, Teknologi Informasi Dan Komunikasi, Bogor: Yudhistira.

Undang-undang Dasar Negara Republik Indonesia Nomor 10 Tahun 1998

Harahap, Sofyan Syafri. 2009. "Analisis Kritis Atas Laporan Keuangan”. Raja Grafindo Persada. Jakarta

Fanani, Zaenal. 2010. "Analisis Faktor-Faktor Penentu Persistensi Laba". Universitas Airlangga. Surabaya

Ikatan Akuntan Indonesia. 2012. Standar Akuntansi Keuangan. IAI. Jakarta

O’Brien, J.A, 2005.

ed. McGraw Hill

Companies, Inc. America

Hendriksen,Eldon S. \& Van Breda,Michael F. 1992, ed. Pennsylvania State University. America

PT.Bank Rakyat Indonesia (Persero) Tbk. 2018. Tentang BRI. http://bri.co.id >tentang-bri (di akses 22 November)

Laporan Keuangan Interim PT. Bank Rakyat Indonesia (Persero) Tbk, 2012. Manajemen PT.BRI sesuai Standar Akuntansi Keuangan di Indonesia

Atkinson, Anthony A. 2007. Management Accounting. Upper Saddle River, N.J. : Pearson Prentice Hall, Inc.America 